\title{
Children with two homes: Psychological problems in relation to living arrangements in Nordic 2- to 9-year-olds
}

\author{
MALIN BERGSTRÖM$M^{1,3}$, EMMA FRANSSON ${ }^{1}$, MICHAEL B. WELLS ${ }^{2}$, \\ LENNART KÖHLER ${ }^{4,5}$ \& ANDERS HJERN ${ }^{1,3}$
}

${ }^{1}$ Centre for Health Equity Studies (CHESS), Stockholm University/Karolinska Institutet, Sweden, 2 Prevention, Intervention, and Mechanisms in Public Health, Department of Public Health Sciences, Karolinska Institutet, Sweden, ${ }^{3}$ Clinical Epidemiology, Department of Medicine, Karolinska Institutet, Sweden, ${ }^{4}$ Nordic School of Public Health, Sweden, and ${ }^{5}$ Epidemiology and Social Medicine, Department of Public Health, Institute of Medicine, The Sahlgrenska Academy at University of Gothenburg, Sweden

\begin{abstract}
Aim: Joint physical custody, children spending equal time in each parents' respective home after a parental divorce, is particularly common in Nordic compared with other Western countries. Older children have been shown to fare well in this practice but for young children there are few existing studies. The aim of this paper is to study psychological problems in 2- to 9-year-old Nordic children in different family forms. Methods: Total symptom score according to the Strengths and Difficulties Questionnaire as well as scores showing externalizing problems were compared among 152 children in joint physical custody, 303 in single care and 3207 in nuclear families through multiple linear regression analyses. Results: Children in single care had more psychological symptoms than those in joint physical custody $(\mathrm{B}=1.08 ; 95 \% \mathrm{CI} 0.48$ to $1.67)$ and those in nuclear families had the least reported symptoms $(\mathrm{B}=-0.53 ; 95 \% \mathrm{CI}-0.89$ to -0.17$)$. Externalizing problems were also lower in nuclear families $(\mathrm{B}=-0.28,95 \% \mathrm{CI}-0.52$ to -0.04$)$ compared with joint physical custody after adjusting for covariates. Conclusions: Young children with non-cohabiting parents suffered from more psychological problems than those in intact families. Children in joint physical custody had a lower total problem score than those in single care after adjusting for covariates. Longitudinal studies with information on family factors before the separation are needed to inform policy of young children's post-separation living arrangements.
\end{abstract}

Keywords: Children, preschoolers, psychological problems, divorce, joint physical custody, parental separation, custody, Strengths and Difficulties Questionnaire, Nordic countries

\section{Background}

During the last 20 years, it has become more common for children in the Western world to experience joint physical custody (JPC) after a parental separation. JPC refers to a practice where children live alternately and equally with both parents; for example, one week with the mother and the next with the father.
The Nordic nations are considered to be the most gender equal countries in the world and have generous family policies encouraging both parents to use parental leave [1]. They also share a political emphasis on the dual earner/dual carer model, which is supported through legislating family policies such as providing general child allowances and tax-funded

Correspondence: Malin Bergström, Centre for Health Equity Studies (CHESS), Stockholm University/Karolinska Institutet, Sveaplan, Stockholm, 10691, Sweden. E-mail: malin.bergstrom@ki.se

Date received 11 March 2017; reviewed 05fanuary 2018; accepted 28 February 2018

(C) Author(s) 2018

Reprints and permissions: sagepub.co.uk/journalsPermissions.nav DOI: $10.1177 / 1403494818769173$

journals.sagepub.com/home/sjp 
preschools [1]. A part of that equality is seen in the number of JPC families, and it is particularly common in Sweden, Norway and Denmark [2]. In Sweden, around $40 \%$ of separated families practice equal JPC for their children [3,4]. There are, to the authors' knowledge, no recent reports of the percentages of children with JPC in Finland and Iceland. While several Western countries, such as the United Kingdom, mainly practice single maternal care, JPC has become more common in countries such as Australia, Belgium and Canada [2,5]. The practice of JPC seems to be on the rise in Europe, since it is more common among young children and parents that have recently separated $[2,4]$. The increase in the number of children living with JPC is one of the biggest changes in Nordic and Western children's living conditions during the last decade. Understanding how children fare in this increasing new family form is an important public health issue.

Several studies have established that children with separated parents show a higher risk for emotional problems and social maladjustment than those with cohabiting parents, as reviewed by Amato [6]. Reasons for this higher risk may be related to children's loss of social, economic and human capital after the divorce [6]. Also, pre-separation characteristics, such as lower parental relationship satisfaction and higher conflict levels, may contribute to children's poorer wellbeing [6]. Young children's development and adjustment of emotional and physiological regulation is influenced by their interaction with parents. Their abilities to cope emotionally and regulate their behaviour during stress are important parts of the socio-emotional development. Difficulties in coping with a living situation may be expressed through problematic externalizing behaviour, such as tantrums and defiant behaviour, or emotionally through sadness or anxiety [7].

Theoretically, the concerns about the suitability of JPC for children of preschool age derive from attachment theory. According to this theory, young children need stability and predictability in their relationships with carers since their first attachment relations are still developing [8]. Especially separation from the mother (often regarded as a primary attachment figure) has been interpreted as a potential threat to children's emotional security and hence their healthy development [9].

Several studies have shown that adolescents and children from around 10 years of age can cope well with the frequent moves and different family situations that is inherent within JPC families [10]. Some of these studies also include younger children. In a review of the literature by Nielsen (2014), 17 of 40 reviewed studies included children aged 9 years or younger; the limited sample sizes do not, however, permit sub-sample analyses [10]. In two recent studies, children from 4 years of age are included, and parental assessments of the Strengths and Difficulties Questionnaire are used as outcomes $[11,12]$. Both studies show that children with JPC have fewer psychological problems than those living with only one parent, but they do not discriminate between different ages in their samples (416 and 4-17 years, respectively). Thus, the existing studies on school aged children cannot provide scientific guidance for how younger children fare in different living arrangements.

While there are a handful of studies that focus on preschool children exclusively [4,13-15], these have been criticized for low methodological quality, small sample sizes and limited generalizability [8]. However, these studies suggest that from around 3 years of age, children in JPC fare better or equally as well as those in single care settings, but the study of the relationship between psychological outcomes and living arrangements is far from satisfactory for young children. Studies of children under 3 years of age are even more scarce.

\section{Aim}

In this study, we wanted to investigate psychological problems in 2- to 9-year-old children in the Nordic countries in relation to their living arrangements. We compared overall psychological problems, as well as externalizing behaviour problems, in children with JPC in the nuclear family and single care setting.

\section{Methods}

\section{Data source}

The Nordic Study of Children's Health and Wellbeing (NordChild) is a cross-sectional survey conducted in Sweden, Denmark, Finland, Iceland and Norway in 1984, 1996 and 2011. Stratified sampling based on age and gender was made from the total population of children. A postal questionnaire including information about the study was sent to the child's registered home address [16]. The questionnaire was directed at the parents, but if they found it appropriate, they could fill it in together with the child.

\section{Participants}

The study used data from the 2011 version of the parent-completed survey with an overall response rate after reminders of $48.8 \%$. This response rate is similar to those in, for example, The Norwegian Mother-Child cohort and The Danish National Birth Cohort. The sample in the current study 
included 38142 - to 9-year-olds. However, 20 parents did not state the child's living arrangements and 132 did not complete the outcome measure. Therefore, the final sample was a total of 3662, including 694 from Sweden, 721 from Iceland, 698 from Norway, 739 from Finland and 810 from Denmark. Ethical permission was granted from the Ethical Permission Boards in each Nordic country.

\section{Categorical variable}

Living arrangements were based on the parents' answers to the question 'with whom does the child live?' and categorized into nuclear families, JPC families and single care families. The category 'JPC' consisted of those who had answered 'the child has joint physical custody' or stated that the parents were separated and that the child lived with both parents with a specified frequency of days in the other parent's home of 145-220 days per year or 12-18 days per month. The JPC and single care groups could consist of a single biological parent with or without a new partner. In this sample, $n=3207$ lived in nuclear families (always together with both original parents), $n=152$ in JPC and $n=303$ only with one biological parent. The questions were completed by the child's father in $22 \%(n=34)$ of the JPC, $14 \%(n=443)$ of the nuclear and $7 \%(n=22)$ of the single care families.

\section{Outcome measures}

We used the Strengths and Difficulties Questionnaire (SDQ), which is a widely used instrument that includes 20 items on psychological problems measured through the subscales: emotional symptoms, conduct problems, hyperactivity/inattention and peer relationship problems, with subscale sum scores ranging from 0 to 10 [17]. It also includes a five-item subscale on prosocial behaviour. The main outcome measure in the present study was the total sum of scores for the four problem scales (ranging from 0 to 40). A high score indicates more psychological problems. A secondary outcome was to only look at externalizing problems via the conduct and hyperactivity/inattention subscales. This second-order subscale has been shown to have good convergent and divergent validity [18]. The Cronbach's alpha for the total sum score was 0.63 , for the externalizing sub-scale 0.76 and for the separate sub-scales: hyperactivity 0.76 , emotional 0.58 , conduct 0.50 , prosocial 0.68 and peer 0.52 .

\section{Covariates}

The covariates included gender of the responding parent, child age and gender, the Nordic country the child lived in, parental educational level and the child's national origin (Nordic/other country).

\section{Statistical analysis}

Sociodemographic characteristics were presented as numbers and percentages and child age as mean and standard deviation. Mean values and standard deviations (SD) were calculated for the total score and for externalizing behaviour, as found via combining the subscales conduct problems and hyperactivity of the SDQ. Linear multiple regression analyses were used to calculate B coefficients on the total sum score of the SDQ and for externalizing problems and those results were compared with the three living arrangements: JPC, single care and nuclear families, with JPC as the reference group. Model 1 adjusted for gender of the responding parent, child age and gender. Model 2 further adjusted for the Nordic country the child lives in and Model 3 additionally adjusted for parental level of education and the child's national origin (Nordic/other country). A total of 3662 children's data were analyzed in these three models. The intraclass correlation for the Nordic countries based on the SDQ total was very small: $\mathrm{ICC}=0.0145$. This means that only $1.45 \%$ of the variance in the SDQ total exists between countries. We therefore chose to conduct linear multiple regressions instead of twolevel analyses.

\section{Results}

\section{Descriptive statistics}

As shown in Table I, most of the children (87.6\%) lived in nuclear, $4.2 \%$ in JPC and $8.3 \%$ in single care families. The vast majority of those in single care lived with their mother. Parents in nuclear households more often had a university degree compared with those in JPC or single care households. While the share of boys in nuclear and single care households were about equal compared to girls, more boys than girls lived in JPC households. Few parents were born outside the Nordic countries $-3.1 \%$ in the nuclear families, $4.7 \%$ in the JPC families and 3.7\% in the single care families - and this proportion did not differ significantly between the three living arrangements. Sweden had the most children living in JPC, and Iceland had the least.

As shown in Table II, children in nuclear families had the lowest mean scores and those in single care households had the highest for all problem subscales and for the total score on the SDQ. Children in JPC families scored in between those in the other two family types. Children in single care families had the 
Table I. Characteristics of children by family type $(N=3662)$.

\begin{tabular}{|c|c|c|c|c|c|c|c|}
\hline & \multicolumn{2}{|c|}{ Nuclear family } & \multicolumn{2}{|c|}{$\begin{array}{l}\text { Joint physical } \\
\text { custody }\end{array}$} & \multicolumn{2}{|c|}{ Single care } & \multirow{2}{*}{$\begin{array}{l}\text { Chi-square } \\
p \text {-value }\end{array}$} \\
\hline & $n$ & $\%$ & $n$ & $\%$ & $n$ & $\%$ & \\
\hline Sample size & 3207 & 87.6 & 152 & 4.2 & 303 & 8.3 & \\
\hline \multicolumn{8}{|l|}{ Resident parent } \\
\hline Mother & NA & & NA & & 287 & 90.3 & \\
\hline Father & NA & & NA & & 31 & 9.7 & \\
\hline Parental education & & & & & & & $<0.001$ \\
\hline University & 1857 & 57.9 & 77 & 50.7 & 116 & 38.3 & \\
\hline High school & 772 & 24.1 & 35 & 23.0 & 90 & 29.7 & \\
\hline Less than high school & 578 & 18.0 & 40 & 26.3 & 97 & 32.0 & \\
\hline Child's sex & & & & & & & NS \\
\hline Girl & 1585 & 49.4 & 63 & 41.4 & 151 & 49.8 & \\
\hline Boy & 1622 & 50.6 & 89 & 58.6 & 152 & 50.2 & \\
\hline Parent country of birth & & & & & & & NS \\
\hline Nordic & 3082 & 96.9 & 143 & 95.3 & 290 & 96.3 & \\
\hline Other & 100 & 3.1 & 7 & 4.7 & 11 & 3.7 & \\
\hline Nordic country & & & & & & & $<0.001$ \\
\hline Sweden & 612 & 19.1 & 50 & 32.9 & 32 & 10.6 & \\
\hline Iceland & 636 & 19.8 & 18 & 11.8 & 67 & 22.1 & \\
\hline Norway & 602 & 18.8 & 34 & 22.4 & 62 & 20.5 & \\
\hline Finland & 636 & 19.8 & 19 & 12.5 & 84 & 27.7 & \\
\hline Denmark & 721 & 22.5 & 31 & 20.4 & 58 & 19.1 & \\
\hline Child age & & & & & & & $t$-test \\
\hline (Mean, SD) & 5.59 & 2.18 & 6.40 & 2.12 & 6.43 & 2.20 & $<0.001$ \\
\hline
\end{tabular}

Table II. Means and standard deviations of psychological problems by family type.

\begin{tabular}{|c|c|c|c|c|c|c|c|}
\hline & \multicolumn{2}{|c|}{$\begin{array}{l}\text { Nuclear family } \\
(n=3207)\end{array}$} & \multicolumn{2}{|c|}{$\begin{array}{l}\text { Joint physical custody } \\
(n=152)\end{array}$} & \multicolumn{2}{|c|}{$\begin{array}{l}\text { Single care } \\
(n=303)\end{array}$} & \multirow[t]{2}{*}{ Cronbach's alpha } \\
\hline & Mean & SD & Mean & $\mathrm{SD}$ & Mean & SD & \\
\hline \multicolumn{8}{|l|}{ Outcome measures } \\
\hline SDQ total score & 6.69 & 4.35 & 7.56 & 4.96 & 8.85 & 5.64 & $\begin{array}{l}0.63 \text { (everything) } \\
0.58 \text { (without peer) }\end{array}$ \\
\hline External behaviour^ (hyperactivity + conduct) & 4.20 & 2.98 & 4.53 & 3.17 & 5.32 & 3.59 & 0.76 \\
\hline \multicolumn{8}{|l|}{ SDQ subscales } \\
\hline Hyperactivity ${ }^{\star \star}$ & 2.78 & 2.15 & 3.03 & 2.21 & 3.59 & 2.49 & 0.76 \\
\hline Emotional $^{\star}$ & 1.34 & 1.52 & 1.66 & 1.63 & 1.90 & 1.88 & 0.58 \\
\hline Conduct ${ }^{\star \star}$ & 1.42 & 1.31 & 1.49 & 1.42 & 1.72 & 1.53 & 0.50 \\
\hline Prosocial & 7.90 & 1.78 & 7.99 & 1.72 & 7.80 & 1.83 & 0.68 \\
\hline Peer ${ }^{\star}$ & 1.17 & 1.44 & 1.44 & 1.67 & 1.65 & 1.67 & 0.52 \\
\hline
\end{tabular}

${ }^{\star} p<0.001 ;{ }^{\star \star} p 0.01$. The bold types are for means, standard deviations are not bold

lowest mean score for the positive prosocial subscale, while JPC families had the highest.

The multiple linear regression analyses of total scores on the SDQ showed that children in single care families had more ( $\mathrm{B}=1.08,95 \%$ CI 0.48 to 1.67 ) and children in nuclear families had less $(B=-0.53$, $95 \%$ CI -0.89 to -0.17 ) symptom loads of psychological problems than children in joint physical custody after adjusting for child age and child gender (Model 1, Table III). Further adjusting for the Nordic country (Model 2), as well as parental education level and being born in a Nordic country (Model 3), did not substantially change the different patterns of SDQ scores in relation to living arrangements. The analyses thus show that children in nuclear families had fewer psychological problems according to their parents' assessments than those with separated parents. Similarly, children in JPC had fewer psychological problems according to their parents than those in single care families. The effect size on SDQ total score of living in JPC compared with single care was $d=0.24$ according to Cohen's effect size. This indicates a moderate effect of living arrangement on children's psychological symptoms [19]. 
Table III. Linear regression models of SDQ Total Score by living arrangements, sociodemographic variables and Nordic country $(n=3662)$.

\begin{tabular}{|c|c|c|c|c|c|c|}
\hline & \multicolumn{2}{|l|}{ Model 1} & \multicolumn{2}{|l|}{ Model 2} & \multicolumn{2}{|l|}{ Model 3} \\
\hline & $\mathbf{B}$ & $\mathrm{CI}$ & B & $\mathrm{CI}$ & $\mathbf{B}$ & $\mathrm{CI}$ \\
\hline \multicolumn{7}{|l|}{ Living arrangement } \\
\hline Joint physical custody & ref & & ref & & ref & \\
\hline Single care & $1.08^{\star \star \star}$ & 0.48 to 1.67 & $.97^{\star \star \star}$ & 0.38 to 1.56 & $0.96^{\star \star \star}$ & 0.37 to 1.54 \\
\hline Nuclear family & $-0.53^{\star \star}$ & -0.89 to -0.17 & $-0.60^{\star \star \star}$ & -0.97 to -0.24 & $-0.51^{\star \star}$ & -0.88 to -0.15 \\
\hline Child age & $-0.07^{\mathrm{t}}$ & -0.13 to 0.00 & $-0.07^{\mathrm{t}}$ & -0.13 to 0.00 & $-0.08^{\star}$ & -0.15 to -0.02 \\
\hline \multicolumn{7}{|l|}{ Child gender } \\
\hline Girl & ref & & ref & & ref & \\
\hline Boy & $1.01^{\star \star \star}$ & 0.71 to 1.30 & $1.04^{\star \star \star}$ & 0.75 to 1.34 & $1.04^{\star \star \star}$ & 0.75 to 1.34 \\
\hline \multicolumn{7}{|l|}{ Nordic country } \\
\hline Sweden & & & ref & & ref & \\
\hline Iceland & & & $1.04^{\star \star \star}$ & 0.56 to 1.52 & $0.96^{\star \star \star}$ & 0.48 to 1.43 \\
\hline Norway & & & 0.24 & -0.24 to 0.72 & 0.18 & -0.30 to 0.66 \\
\hline Finland & & & $1.47^{\star \star \star}$ & 1.00 to 1.95 & $1.40^{\star \star \star}$ & 0.93 to 1.88 \\
\hline Denmark & & & $0.56^{\star}$ & 0.09 to 1.03 & $0.58^{\star}$ & 0.12 to 1.04 \\
\hline \multicolumn{7}{|l|}{ Parental education } \\
\hline University & & & & & ref & \\
\hline High school & & & & & $0.52^{\star \star \star}$ & 0.20 to 0.84 \\
\hline Less than high school & & & & & $2.54^{\star \star \star}$ & 1.83 to 3.24 \\
\hline \multicolumn{7}{|l|}{ National origin } \\
\hline Nordic & & & & & ref & \\
\hline Other & & & & & $0.95^{\star}$ & 0.10 to 1.80 \\
\hline
\end{tabular}

$t<0.10 ;{ }^{\star} p<0.05 ;{ }^{\star \star} p<0.01 ;{ }^{\star \star \star} p<0.001$.

Boys had higher SDQ total scores than girls $(\mathrm{B}=$ $1.01,95 \%$ CI 0.71 to 1.30 ), while child age was a trend in Model 1 and Model 2 and became significant in Model 3. Here, older children had fewer reported psychological problems $(\mathrm{B}=-0.08,95 \%$ $\mathrm{CI}-0.15$ to -0.02 ) than younger children. In Model 2 , children with parents with a high school $(\mathrm{B}=$ $0.52,95 \%$ CI 0.20 to 0.84 ) or less than a high school (B $=2.54,95 \%$ CI 1.83 to 3.24$)$ education level were reported to have more psychological problems than those born to parents with a university education. Also, having parents that were born outside the Nordic countries was associated with higher symptom loads of psychological problems in children ( $\mathrm{B}=0.95,95 \% \mathrm{CI} 0.10$ to 1.80 ), as was living in Iceland ( $\mathrm{B}=1.04,95 \% \mathrm{CI} 0.56$ to 1.52$)$, Finland $(\mathrm{B}=1.47,95 \% \mathrm{CI} 1.00$ to 1.95$)$ or Denmark (B $=0.56,95 \%$ CI 0.09 to 1.03 ) compared with Sweden (Model 3).

The multiple analyses of children's externalizing problems in Table IV show a similar pattern in relation to living arrangements as children's total psychological problems. However, after adjusting for sociodemographic confounders, the externalizing symptom load for children in single care households was no longer statistically significantly different from children in JPC (B $=0.38,95 \%$ CI -0.01 to 0.77 ), while children in nuclear families showed less externalizing symptoms $(B=-0.28,95 \%$ CI -0.52 to -0.04$)$ than the children with non-cohabiting parents.

\section{Discussion}

Using nationally representative data that was gathered simultaneously from the five Nordic countries, the current study sought to cross-sectionally assess parents' perceptions of their 2- to 9- year old childrens' psychological problems, with particular focus on the child's living arrangements. Children in joint physical custody, living more or less equally with both parents, suffered from less psychological problems than those in single care after adjusting for covariates.

The findings of this study outline a similar pattern among young children as those reported for school aged and adolescent children [3]. Children in JPC are in an intermediate position between children in nuclear families, having the least, and those in single care, having the most problems, as shown in earlier publications from our group as well as from other research groups [11,12].

Since young children are more heavily influenced by their parents than older children, living with both parents may shelter the child from the losses 
Table IV. Linear regression models of Externalizing Behaviour via the SDQ subscales conduct problems and hyperactivity by living arrangements, sociodemographic variables and Nordic country $(n=3662)$.

\begin{tabular}{|c|c|c|c|c|c|c|}
\hline & \multicolumn{2}{|l|}{ Model 1} & \multicolumn{2}{|l|}{ Model 2} & \multicolumn{2}{|l|}{ Model 3} \\
\hline & $\mathbf{B}$ & $\mathrm{CI}$ & $\mathbf{B}$ & CI & $\mathbf{B}$ & $\mathrm{CI}$ \\
\hline \multicolumn{7}{|l|}{ Living arrangement } \\
\hline Joint physical custody & ref & & ref & & ref & \\
\hline Single care & $0.43^{\star}$ & 0.04 to 0.83 & $0.38^{\mathrm{t}}$ & -0.01 to 0.78 & $0.38^{\mathrm{t}}$ & -0.01 to 0.77 \\
\hline Nuclear family & $-0.30^{\star}$ & -0.54 to -0.06 & $-0.34^{\star \star}$ & -0.58 to -0.09 & $-0.28^{\star}$ & -0.52 to -0.04 \\
\hline Child age & $-0.10^{\star \star \star}$ & -0.15 to 0.06 & $-0.10^{\star \star \star}$ & -0.15 to -0.06 & $-0.11^{\star \star \star}$ & -0.16 to -0.07 \\
\hline \multicolumn{7}{|l|}{ Child gender } \\
\hline Girl & ref & & ref & & ref & \\
\hline Boy & $0.91^{\star \star \star}$ & 0.71 to 1.11 & $0.93^{\star \star \star}$ & 0.73 to 1.13 & $0.93^{\star \star \star}$ & 0.73 to 1.12 \\
\hline \multicolumn{7}{|l|}{ Nordic country } \\
\hline Sweden & & & ref & & ref & \\
\hline Iceland & & & $0.36^{\star}$ & 0.04 to 0.68 & $0.33^{\star}$ & 0.01 to 0.65 \\
\hline Norway & & & 0.09 & -0.23 to 0.41 & 0.08 & -0.25 to 0.40 \\
\hline Finland & & & $0.77^{\star \star \star}$ & 0.45 to 1.09 & $0.71^{\star \star \star}$ & 0.39 to 1.03 \\
\hline Denmark & & & 0.19 & -0.12 to 0.50 & 0.20 & -0.12 to 0.51 \\
\hline \multicolumn{7}{|l|}{ Parental education } \\
\hline University & & & & & ref & \\
\hline High school & & & & & $0.42^{\star \star \star}$ & 0.21 to 0.63 \\
\hline Less than high school & & & & & $1.36^{\star \star \star}$ & 0.89 to 1.82 \\
\hline \multicolumn{7}{|l|}{ National origin } \\
\hline Nordic & & & & & ref & \\
\hline Other & & & & & 0.37 & -0.20 to 0.93 \\
\hline
\end{tabular}

$t<0.10 ;{ }^{\star} p<0.05 ;{ }^{\star \star} p<0.01 ;{ }^{\star \star \star}<0.001$.

previously described as associated with a parental split up $[8,9,19]$. It has also been argued that continuous and frequent caregiving is necessary for a parent to develop sensitive parenting adapted to the unique child, and JPC may increase parents' possibilities to develop that [20]. Earlier publications have shown higher life satisfaction and lower risks for mental and physical health problems in parents with JPC compared with single care [11]. Since such factors directly affect children's psychological symptoms, this may help to explain the associations found in this study $[21,22]$.

Interview studies with older children have shown that JPC may impose hassles such as long distances to school, friends and leisure activities [23]. Since younger children rely on their parents for such logistics to a higher degree than older ones, it is possible that the hassles of moving between homes are less burdensome for them. Taken together, the results of this study indicate that the potential stress from living in two homes does not add to the potential emotional problems from having experienced separation or divorce of parents.

The critique against the practice of JPC has, on the other hand, mostly been targeted at families with preschoolers and young children $[8,9,24]$. Young children are assumed to have a greater need for stability and continuity with a predictive caregiver than older children. Child experts have therefore been cautious in advocating this practice for young children since it implies frequent separations $[8,9,24]$. The intense debate about young children's wellbeing in JPC has had consequences for public policy, family legislation and court decisions on individual children's family forms, despite the scarcity of high-quality studies $[8,9,13-15,24]$. However, the results of this study do not confirm such concerns, as children in JPC families fared as well as or better than those living with only one parent.

Since JPC is an increasingly common living condition for children in many Western countries $[2,3]$ and concerns every tenth Swedish child aged 12-15 [3], empirical knowledge of children's wellbeing in relation to living arrangements is important from a public health perspective. Factors that are affectable, such as who the child lives with when their parents do not live together, are especially interesting in public health studies since they can influence policies and public opinion.

\section{Methodological issues}

We had the advantage of using a nationally representative survey conducted simultaneously in the Nordic countries with a well-used and validated outcome measure on psychological problems. The relatively 
large proportion of children in JPC in the Nordic countries allowed us to assess associations between living arrangement and psychological problems for 2- to 9-year-old children. However, the external loss of the survey was high and may be biased by a selective attrition of families with low socioeconomic resources and migrant background. Accordingly, our results should not automatically be generalized to these disadvantaged families.

The inclusion of children from 2 to 9 years of age is a considerable strength of this study. Research on the wellbeing of children under 10 years of age in relation to living arrangements is scarce, and previous studies include non-representative samples or children who do not share their time between their parents' homes in the JPC category [10]. Hence, our categorization of JPC as spending $40-60 \%$ of these young children's time in the respective parent's homes is a considerable strength. Due to the small sample sizes, we were unable to conduct interaction analyses of the different age groups. The general results of this study can therefore not be applied to children's specific ages.

The findings of no statistically significant differences regarding externalizing behaviours between children in the two post-separation arrangements are interesting, as they might indicate that younger children show more problematic behaviours after a parental separation, regardless of family form. In this study we could not include a measure of time since parental separation. Due to the relatively low age of the children, it is possible that the parental separations were recent in time, and children may not have had time to settle into their new family form. It may however be possible that the proportions of children in JPC and single care did not render sufficient statistical power to detect potentially significant differences between these groups regarding externalizing symptoms. Furthermore, it was not possible from available data to show if the post-separation parents really lived alone with the child or had a new partner. The identified difference between children in nuclear families and the two post-separation family types is in line with earlier findings of children regarding behavioural adaptation [20-21]. These studies of older school-aged children and adolescents show that risks for externalizing problems and risk behaviours are lower for children in JPC than for those in single care families. Our finding thus needs to be replicated in order to determine whether it could be a temporary reaction in younger populations or something persistent for externalizing behaviours.

The instructions for the questionnaire were directed at the parents and due to the low ages of the children we assume that they were not involved in answering the questionnaires. This may bias the answers since parents with mental ill-health may assess their children's behaviour as more problematic. These results are, however, in accordance with publications where school children themselves have answered the questions $(3,21)$. There may also be a gender selection among the responding parents. Fathers who are engaged in parenthood are more prone to participate in parental surveys than those who are less engaged [25]. Fathers with children in JPC often are more involved in parenting on an everyday basis compared with families where children live only or mostly with their mother, and more fathers with children in JPC completed the survey $(n=34)$ compared with fathers of children in single care $(n=22)$.

Despite being able to control for parental characteristics, such as country of origin and educational level, the cross-sectional design of this study implies that our results may still be affected by family factors not included in the data collection. Possibly, there may be a selection into different family forms and pre-separation family characteristics may influence children's subsequent living arrangements. Parents who divorce suffer from more psychological problems and have poorer socioeconomic circumstances than parents who stay together. Obviously, they also more often have conflicts and relationship problems that precede the separation as well as higher risks for post-divorce conflicts and difficulties when agreeing on children's custody and living arrangements [11,26-28]. Since the effect size of post-separation living arrangement was moderate, it is plausible that family factors beyond those assessed here have an effect on children's psychological symptoms.

This study design does not allow causal interpretation and it is possible that children who suffer from psychological problems, even this young, are at greater risk of experiencing a parental divorce and end up living with only one of their parents. Future studies should preferably include longitudinal data with more detailed information on custody and living arrangement histories.

Compared with single maternal care after a parental separation or divorce, JPC is more common in the Nordic countries than in other Western countries $[1,2]$. Since children's psychological problems, as well as parents' wellbeing, may be related to social acceptance and the commonness of their family form in their everyday context, the results of this study may not be generalizable to young children in environments where JPC is less common and potentially less accepted and acknowledged. It is possible that effects of JPC vary by country contexts. Further studies, with larger sample sizes, are needed to investigate these patterns using a two-level design. 


\section{Conclusions}

Young children with non-cohabiting parents suffered from more psychological problems than those in intact families. Children in joint physical custody suffered from fewer psychological problems than those in single care families, while externalizing problems were similar in the two post-separation groups after adjusting for covariates. Longitudinal studies with information on family factors before the separation are needed to inform policy on young children's post-separation living arrangements.

\section{Acknowledgements}

We are grateful for the contribution from the members of the NordChild network to this project.

\section{Authors' contributions}

LK designed and led the original NordChild study from the Nordic School of Public Health. MB conceived the study, participated in the design, co-performed the statistical analyses and drafted the manuscript. MW co-performed the statistical analyses and co-authored the manuscript. EF participated in the design of the study, interpretation of the data and co-authored the manuscript. AH participated in the design, interpretation of the data and co-authored the manuscript. All authors read and approved the final manuscript.

\section{Declaration of Conflicting Interests}

The author(s) declared no potential conflicts of interest with respect to the research, authorship, and/ or publication of this article.

\section{Funding}

The author(s) disclosed receipt of the following financial support for the research, authorship, and/or publication of this article: This work was supported by Länsförsäkringsbolagens Forskningsfond.

\section{References}

[1] Gíslason IV and Björk Eydal G (eds) Parental leave, childcare and gender equality in the Nordic countries - TemaNord. Copenhagen: Nordic Council of Ministers, 2011, p. 562.

[2] Fehlberg B, Smyth B, Maclean M, et al. Family Policy Briefing 7 - Legislating to encourage shared time. Oxford: Department of Social Policy and Intervention, University of Oxford, 2011.

[3] Bergström M, Modin B, Fransson E, et al. Living in two homes: a Swedish national survey of wellbeing in 12 and 15 year olds with joint physical custody. BMC Pub Health 2013:13:868.

[4] Bergström M, Fransson E, Fabian H, et al. Pre-school children living in joint physical custody arrangements show less psychological symptoms than those living mostly or only with one parent. Acta Paediatr. Epub ahead of print 7 September 2017. DOI: 10.1111/apa.14004
[5] Sodermans K, Vanassche S and Matthijs K. Post-divorce custody arrangements and binuclear family structures of Flemish adolescents Dem Res 2013;28:421-32.

[6] Amato PR and Soblowski JM. The effects of divorce and marital discord on adult children's psychological well-being. Am Soc Rev 2001;66:900-21.

[7] Eisenberg N, Gershoff ET, Fabes RA, et al. Mothers' emotional expressivity and children's behavior problems and social competence: mediation through children's regulation. Psych 2001;37:475-90.

[8] Warshak RA. Social science and parenting plans for young children: a consensus report. Psych Pub Policy Law 2014;20:46-67.

[9] Pruett MK, McIntosh JE and Kelly JB. Parental separation and overnight care of young children, Part I: consensus through theoretical and empirical integration. Fam Court Rev 2014;52:240-55.

[10] Nielsen L. Shared physical custody: summary of 40 studies on outcomes for children. $\mathcal{F}$ Div Remar 2014;55:613-35.

[11] Bergström M, Fransson E, Hjern A, et al. Mental health in Swedish children living in joint physical custody and their parents' life satisfaction: a cross-sectional study. Scand F Psychol 2014;55:433-9.

[12] Westphal S and Monden C. Shared residence for children of divorce: testing the critics' concerns. In: Westphal SK (ed.) Are the kids alright? Essays on postdivorce residence arrangements and children's well-being. Utrecht: Utrecht University, 2015:61-82.

[13] Pruett MK, Ebling R and Insabella G. Critical aspects of parenting plans for young children: interjecting data into the debate about overnights. Fam Court Rev 2004;42:39-59.

[14] McIntosh J, Smyth B, Kelahar M, et al. Post-separation parenting arrangements and developmental outcomes for infants and children. Collected reports. Three reports prepared for the Australian Government Attorney-General's Department, Canberra. Sydney: Family Transitions, 2010.

[15] Tornello SL, Emery R, Rowen J, et al. Overnight custody arrangements, attachment, and adjustment among very young children. F Mar Fam 2013;75:871-85.

[16] Köhler L. NHV and child public health. Scand f Public Health 2015;43:29-32.

[17] Malmberg M, Rydell AM and Smedje H. Validity of the Swedish version of the Strengths and Difficulties Questionnaire (SDQ-Swe) Nord f Psych 2003;57:357-63.

[18] Goodman A, Lamping DL and Ploubidis GB. When to use broader internalising and externalising subscales instead of the hypothesised five subscales on the Strengths and Difficulties Questionnaire (SDQ): data from British parents, teachers and children. $\mathcal{F}$ Abn Child Psych 2010;38:1179-91.

[19] Amato PR. The well-being of children with gay and lesbian parents. Soc Sci Res 2012;41:771-4.

[20] Baude A, Pearson J and Drapeau S. Child adjustment in joint physical custody versus sole custody: a meta-analytic review. F Div Remar 2016;57(5):338-60.

[21] Carlsund A, Eriksson U, Löfstedt P, et al. Risk behaviour in Swedish adolescents: is shared physical custody after divorce a risk or a protective factor? Eur $\mathcal{f}$ Pub Health 2012;23:3-8.

[22] Lansford JE. Parental divorce and children's adjustment. Perspect Psych Sci 2009;4:140-52.

[23] Campo M, Fehlberg B, Millward C, et al. Shared parenting time in Australia: exploring children's views. $\mathcal{F}$ Soc Welfare Fam Law 2012;34:295-313.

[24] Norsk Psykolog Forening. Samvær 0-3. Anbefalinger om samvær for de minste barna etter lov om barn og foreldre [Visitation $0-3$. Recommendations regarding parenting visitation for the youngest children under the Act on Children and Parents]. Oslo: Norsk Psykolog Forening, 2014. 
[25] Bastaits K, Pasteels I, Ponnet K, et al. Adult non-response bias from a child perspective. Using child reports to estimate father's non-response. Soc Sci Res 2015;49: $31-41$.

[26] Melli M and Brown P. Exploring a new family form : the shared time family. Intl f Law Pol Fam 2008;22:231-69.

[27] Gähler M. Life after divorce: economic, social and psychological well-being among Swedish adults and children following family dissolution. PhD Thesis, Stockholm University, 1998.

[28] Rejmer A. Vårdnadstvister: En rättssociologisk studie av tingsrätts funktion vid handläggning av vårdnadskonflikter med utgångspunkt från barnets bästa. [Custody disputes: a socio-legal study of the role of district courts in the handling of custody disputes with the child's best interest as a base]. University of Lund, 2003. 